\title{
ENVIRONMENTAL PERFORMANCE OF KETTLE PRODUCTION: PRODUCT LIFE CYCLE ASSESSMENT
}

\author{
Andrzej MARCINKOWSKI, Krzysztof ZYCH \\ Lodz University of Technology
}

\begin{abstract}
:
The main objective of this paper is to compare the environmental impact caused by two different types of water boiling processes. The aim was achieved thanks to product life cycle assessment (LCA) conducted for stovetop and electric kettles. A literature review was carried out. A research model was worked out on the basis of data available in literature as well as additional experiments. In order to have a better opportunity to compare LCA results with reviewed literature, eco-indicator 99 assessment method was chosen. The functional unit included production, usage and waste disposal of each product (according to from cradle to grave approach) where the main function is boiling 3360 I of water during 4year period of time. A very detailed life cycle inventory was carried out. The mass of components was determined with accuracy of three decimal places $(0.001 \mathrm{~g})$. The majority of environmental impact is caused by electricity or natural gas consumption during usage stage: $92 \%$ in case of the electric and kettle and $99 \%$ in case of stovetop one. Assembly stage contributed in $7 \%$ and $0.8 \%$ respectively. Uncertainty and sensitivity analyses took into consideration various waste scenario patterns as well as demand for transport. Environmental impact turned out to be strongly sensitive to a chosen pattern of energy delivery (electricity mix) which determined final comparison results. Basing on LCA results, some improvements of products were suggested. The boiling time optimization was pointed out for electric kettle's efficiency improvement. Obtained results can be used by manufacturers in order to improve their eco-effectiveness. Moreover, conclusions following the research part can influence the future choices of home appliances users.
\end{abstract}

Key words: comparative analysis, eco-efficiency, environmental management, environmental performance, life cycle assessment $L C A$, production, water boiling process

\section{INTRODUCTION}

Economic development results in increased human impact on the environment, as the production scale is larger. Production companies are forced to face more and more strict requirements (legal, economic, social, environmental, etc.), which should be taken under consideration for planning and running production processes. In order to simplify the implementation of organizational system that can facilitate the achievement of both production and environmental targets, guidelines for environmental management systems (EMS) have been developed. Nowadays managers can use popular standards to systematize all tasks associated with environmental impact of the company and integrate them with overall management system. Series of ISO 14000 $[5,6]$ as well as EMAS Regulation [13] are examples of such standards.

After the years of continual improvement, running environmental programmes and achieving objectives and targets, a very high level of environmental performance can be achieved. In such cases, significant environmental aspects may result less from direct industrial activities (impact fields which had been successfully improved), and more from indirect environmental aspects. The latter are related to the supply chain (the activity of external companies which provide raw materials and media), products distribution, phase of products usage and disposal. A profound analysis of a given product may reveal that the most im- portant environmental impacts result not from industrial activities of the producer but from the other stage of the product life cycle $[1,9,10]$. The analysis like this needs "from cradle to grave" approach and usually is performed according to life cycle assessment (LCA) methodology [3, 4]. LCA provides a very wide perspective that includes various life cycle phases, like:

- acquisition of resources (metal ores, crude oil, coal extraction processes, etc.),

- raw materials production, from which the final product is being made (production processes of metals, alloys, plastic, ceramic, etc.),

- raw materials, materials and semi-products transport (influence of transport means on the environment),

- final product manufacturing processes (direct environmental impact of the product manufacturer),

- packaging production,

- product distribution (supplying the product to wholesaler's, chain stores and customers - environmental impact of transport),

- phase of product usage (materials needed, energy consumption)

- waste disposal - getting rid of the product, packaging and materials after being used (environment impact of disposal methods such as re-use, recycling, landfill processes, waste incineration, etc.). 
The environmental impact of the above-mentioned stages of the product life cycle usually depends mostly on the designer, who by his decisions determines: raw materials usage, energy consumption, etc. Design phase role grows to the most important from the environmental impact's point of view.

The importance of water boiling process for the human civilization is unquestionable. Thanks to water boiling we can fight the presence of bacteria that can easily spread through water, thus avoiding possible health consequences. Disinfection properties of water boiling have taken on special significance in medieval ages. Primitive sanitary conditions together with growing importance of cities (gathering people) created favorable conditions for spreading infectious diseases and epidemic. Even nowadays providing access to sanitation for all is still one of the toughest challenges faced worldwide (also being one of the Sustainable Development Goals) which means that the importance of water boiling is far beyond the demand for warm drinks.

The oldest surviving kettle like device is dated for 3500 to 2000 BC [8]. Stovetop kettles changed over the course of the years, and finally during the XX century, they started to be gradually replaced with the electric ones (firstly invented in the late XIX century) [11]. Due to the increasing environmental concerns and thanks to the presence of proper tools and software, we are now able to test if the previously decisive convenience issues go hand in hand with sustainability indicators. In the era of maximizing efficiency and awareness of limited availability of raw materials, we are obligated to examine products in terms of eco-design. Testing alternatives, reducing the natural resources usage and analyzing possible scenarios should precede each product market entry.

Market of household appliances is expected to reach a value of 343.98 Billion USD by 2020 [16]. For example, according to statista.com the number of TV households as for 2016 have reached nearly 1.6 billion worldwide. We can surely assume that households equipped with kettles outnumber those with TV sets as kettles belong to more affordable goods. The size of home appliances market clearly reflects the demand for research and potential for reducing the environmental pressure by introducing more eco-friendly solutions.

There are numerous to date articles in which LCA research is used for the purpose of comparing alternative products, including those manufactured for households or at least for every day human use. However, papers on LCA of kettles are rather rare and can be found in non-indexed local magazines. The results shown in articles existing to date do not seem to precisely answer the research questions of the following study. Due to the abovementioned, decision was made to update the knowledge on the topic by carrying out a new research.

The main objective of this paper is to compare the environmental impact caused by the process of boiling water using stovetop and electric kettles. The aim is to be achieved thanks to LCA research conducted for each type of water boiling process. Obtained results can be used by manufacturers in order to improve their eco-effectiveness. Moreover, conclusions that will follow can influence the future choices of home appliances users.

\section{LITERATURE REVIEW}

There are numerous papers that include research results concerning environmental impact assessment of various households appliances. Most of them show that the most significant environmental impact results from usage stage of product and is connected with energy consumption $[1,9,10]$. Reduction of energy consumption is a very effective way to achieve better environmental efficiency of products [2].

Among the previously made research works one can also find such dealing with kettles. Murray et al. (2016) underlines the worrying level of energy efficiency improvement in electric kettles compared to other electric home appliances. Authors also point out that the market of electric kettles lacks proper efficiency labeling. Moreover, overfilling the kettles to the unnecessary level is rather common which contributes to the excessive energy consumption. The results of the research are expressed by the amount of energy that can be possibly saved. The average amount of energy saved per one household during one-year period equals $40 \mathrm{kWh}$. Conclusions also point out the importance of avoiding reheating the water shortly after it has boiled [12].

Grzesik et al. (2011) presents results of LCA research for one of the kettles manufactured in Poland. The results have shown that the waste scenario does not play a key role when looking holistically at the LCA. Moreover, it has been stated that the usage phase of the life cycle is the most harmful for the environment. Authors placed focus on optimizing electricity consumption due to the fact that it was responsible for $99 \%$ of the environmental impact. However, electricity amount seems to be determined not very precisely on basis of product nominal power (1900 W) and boiling time (4 minutes) [9].

The comparison of environmental impact of two types of water boiling appliances was the objective of the article by Ayoub et al. (2014). The analysis was based on the cradle to grave principle. The results are clearly unilateral the environmental impact of electric kettle outweighs the stovetop one in every category. It has been also found that in both cases the highest impact is connected to the usage phase of the life cycle. Authors recommend using rather stovetop kettles and including higher percent of renewable energy in the energy mix [1]. However, it seems the research was conducted under a few doubtful assumptions:

- aluminum was assumed as raw material for electric heater production (that could lead to serious assembly error),

- energy amount was determined on basis of boiling time that was astonishingly short (1 minute for electric kettle, 2 minutes for stovetop one),

- only three impact categories (climate change, freshwater eutrophication, and particulate matter formation) were taken into consideration,

- waste scenario was simplified to incineration only (no recycling or landfill).

\section{INPUT DATA AND MODEL ASSUMPTION}

Products' life cycles were assumed to consist of three stages: assembly (including environmental impact of resources extraction, raw material processing and kettle production - from cradle to gate approach), usage stage (predominated by electricity consumption), waste scenario (environmental impact of waste product disposal). 
Mass and materials used for components production of stovetop and electric kettle are depicted in the Table 1 and Table 2. All of the components have been weighed on precise laboratory scales with accuracy of three decimal places (0.001 g). The data provided proper input for the assembly phase.

Table 1

Raw materials used for electric kettle production

\begin{tabular}{ll}
\hline \multicolumn{1}{c}{ Raw material } & \multicolumn{1}{c}{ Mass } \\
\hline Stainless steel & $546.246 \mathrm{~g}$ \\
Steel & $1.572 \mathrm{~g}$ \\
Copper & $17.046 \mathrm{~g}$ \\
Brass & $10.303 \mathrm{~g}$ \\
Nickel & $70.938 \mathrm{~g}$ \\
Chromium & $17.734 \mathrm{~g}$ \\
Polypropylene & $758.319 \mathrm{~g}$ \\
Polyethylene & $1.360 \mathrm{~g}$ \\
Polyvinyl chloride & $80.047 \mathrm{~g}$ \\
Silicone & $26.629 \mathrm{~g}$ \\
Textiles & $0.503 \mathrm{~g}$ \\
Overall weight & $1530.697 \mathrm{~g}$ \\
\hline
\end{tabular}

Table 2

Raw materials used for stovetop kettle production

\begin{tabular}{ll}
\hline \multicolumn{1}{c}{ Raw material } & \multicolumn{1}{c}{ Mass } \\
\hline Aluminum & $231.446 \mathrm{~g}$ \\
Steel & $17.292 \mathrm{~g}$ \\
Polypropylene & $78.745 \mathrm{~g}$ \\
Overall weight & $327.483 \mathrm{~g}$ \\
\hline
\end{tabular}

The manufacturing process (assembly) is assumed to use $50 \mathrm{~kJ}$ of electricity for production of each kettle, and additionally $0.6 \mathrm{I}$ of compressed air in case of electric one [1].

Assumptions for the usage stage included estimation of average volume of water to boil, boiling frequency, efficiency of the process as well as lifespan of products. The maximum capacity of products were not taken into account because usually kettles are not filled up totally and energy consumption results from amount of water to boil. As in reviewed papers the amount of water was different $(0.5$ I [1] and 1.0 I [9]), 0.8 I was assumed here - the volume taken from this range. The average boiling frequency was assumed in accordance with previous researches -3 times a day, the lifespan included 350 days a year (vacation days deducted) during 4 years of usage (4-5 years according to literature $[1,9])$. The initial temperature of water to boil was assumed on the level of legal standard indoor temperature for living rooms and kitchens in domestic conditions [14]. Total energy consumption was determined on basis on volume of boiling water $(0.8 \mathrm{I} \times 3 \times 350 \times 4=3360 \mathrm{l})$, specific heat for water $4.19 \mathrm{~kJ} /(\mathrm{kg} \cdot \mathrm{K})$, temperature difference $\left(100^{\circ} \mathrm{C}-20^{\circ} \mathrm{C}\right)$ and boiling efficiency $(0.83$ and 0.45 for electric and traditional kettles respectively) that were determined basing on separate experiments. In case of stovetop kettle, calorific value of natural gas was assumed (39
$\mathrm{MJ} / \mathrm{m}^{3}$ [15]). It is also important to emphasize that the boiling efficiency of electric kettle is noticeably higher than in the case of traditional one.

As far as the environmental impact of transport is concerned, it is assumed here that both kettles are manufactured in the same place in Europe. Similar distances are involved in life cycles of analyzed products (transport of resources, raw materials and components, distribution, waste transport). Thus, the amount of transport needed is proportional to mass of kettles only.

Assumptions for the waste disposal stage included waste scenario patterns for particular components of products. It was assumed that some proportion of waste materials will undergo recycling whereas the rest will be transferred to landfill. The percentage ratio was fixed to 50\%:50\% for parts made of metals and alloys and 25\%:75\% for components made of other materials. The difference reflects probability of recycling: metal scrap has higher economic value than plastic waste, thus greater percentage of metal is assumed to undergo recycling (50\%) compared to plastics (25\%).

On the basis of the above assumptions, a functional unit for both kettles was determined to enable environmental impact comparison. The unit includes production, usage and waste disposal of each kettle (from cradle to grave approach) where the main function is boiling 3360 I of water during 4-year period of time.

In order to have a better opportunity to compare LCA results with reviewed literature, the same assessment method was chosen as in [9], namely eco-indicator 99 including eleven impact categories. Unfortunately, in [1] only three impact categories were taken into consideration.

\section{LCA RESULTS AND DISCUSSION}

\section{Electric kettle}

Fig. 1 presents the process network for environmental impact of electric kettle assembly phase.

The thickness of arrows represents the contribution of the part to the overall environmental impact. It is worth noticing that two thickest arrows come from polypropylene and nickel which respectively weigh $758 \mathrm{~g}$ and $71 \mathrm{~g}$. Comparing the mass may lead to a conclusion that relatively small amount of nickel causes quite a big threat for environment $(29 \%)$ so replacing it with a substitute is worth considering. Significant environmental load resulting from nickel application confirms results obtained by [9].

The process network for electric kettle life cycle is depicted on Fig. 2. The majority of environmental impact is related to the electricity consumption during usage stage (over $92 \%$ ). The production phase contributes in only $7 \%$ of entire environmental load. Waste scenario and transport processes seem to be negligible $(0.17 \%$ and $0.09 \%$ respectively).

Fig. 3 presents the normalization indicators. For $11 \mathrm{im}$ pact categories the greatest indicators are associated with respiratory inorganics (which represent particulate matter resulting from the burning of fossil fuels emission of sulphate and nitrate aerosols that cause breathing difficulties), carcinogens, climate change and fossil fuels depletion (similar results compared to [9]). The four categories indicate over $93 \%$ of total impact. 


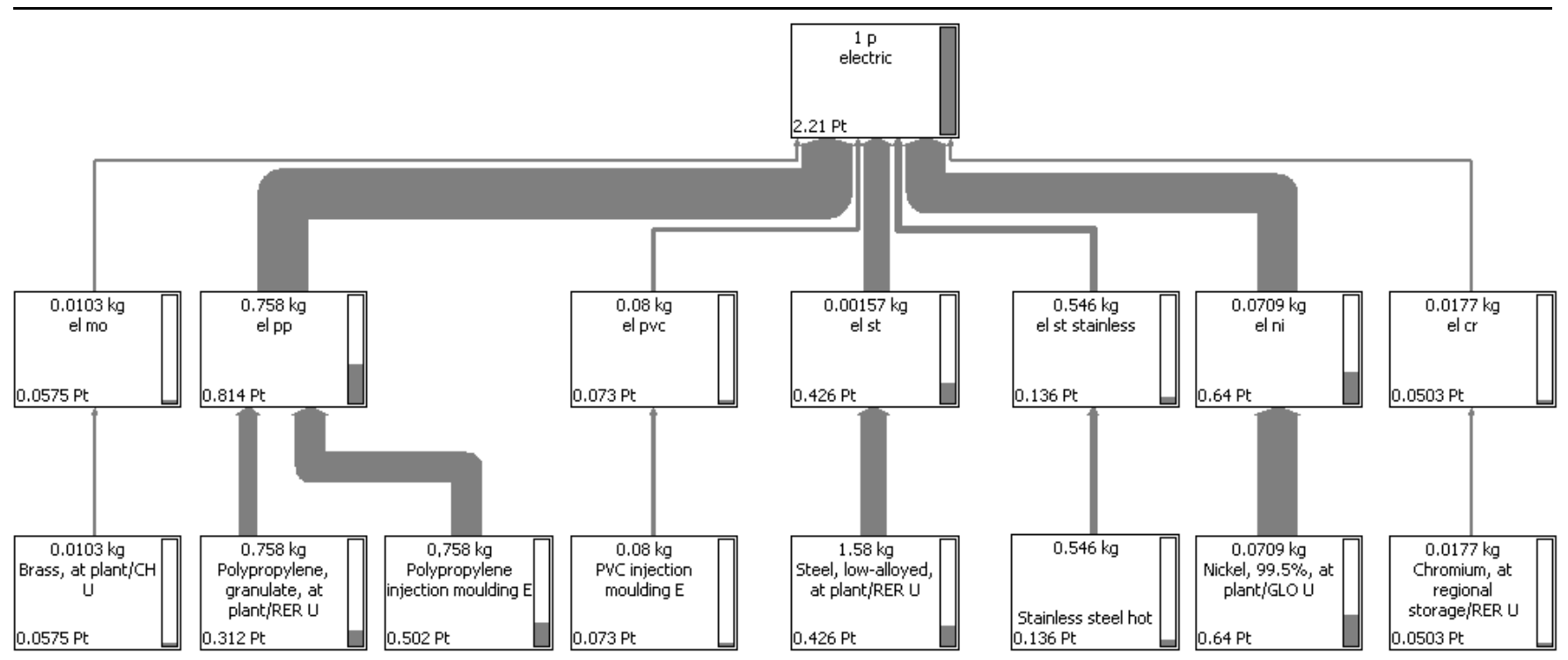

\section{Fig. 1 Process network for assembly stage of electric kettle}

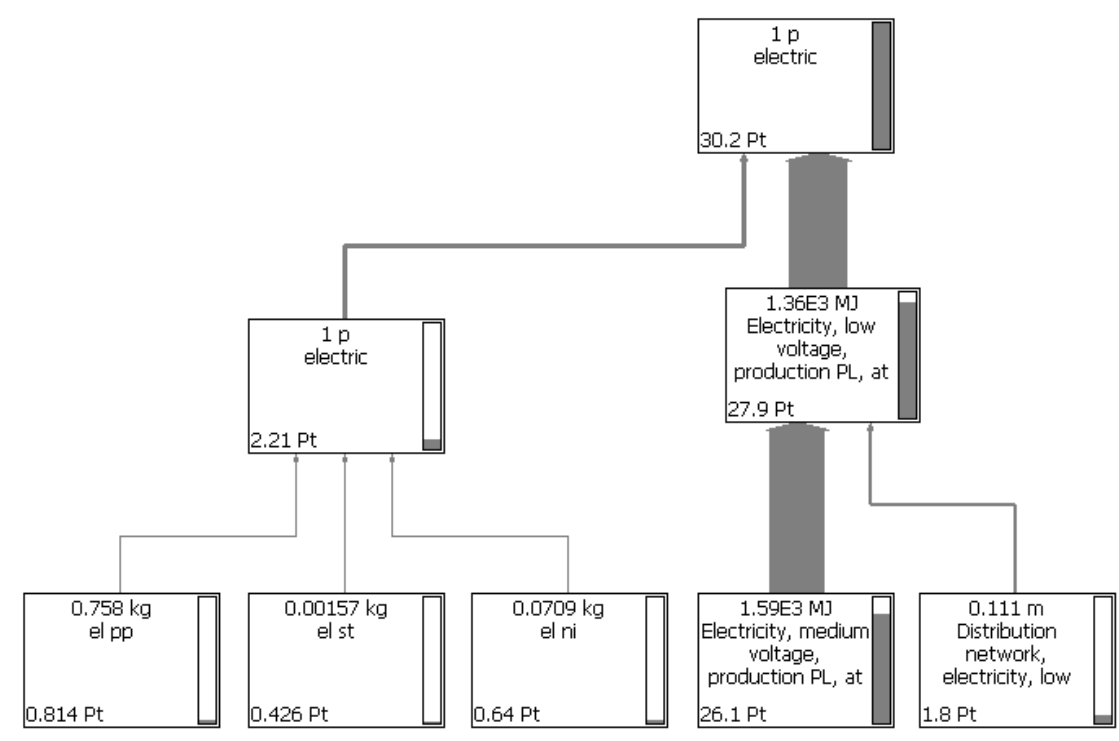

Fig. 2 Process network for life cycle of electric kettle

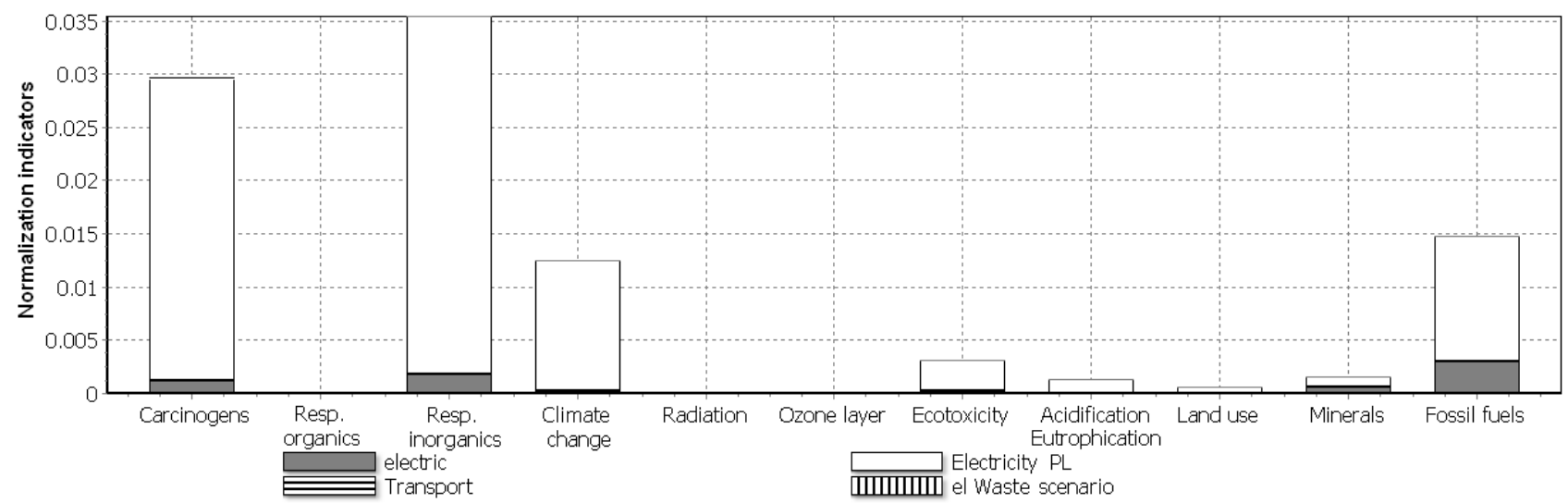

Fig. 3 Normalization indicators for life cycle of electric kettle

\section{Stovetop kettle}

The environmental load of stovetop kettle is presented on Fig. 4 by life cycle process network. Assembly of the traditional kettle is simple and requires only widely used materials (aluminum, polypropylene, steel). Its contribution to total environmental impact is low and does not exceed
$0.8 \%$. Similarly to electric kettle case, environmental loads of waste scenario and transport processes are quite negligible (below $0.3 \%$ ). Indicators are predominated by energy consumption during usage stage of stovetop kettle that is connected with gas burning needed for water boiling (99.2\%). 


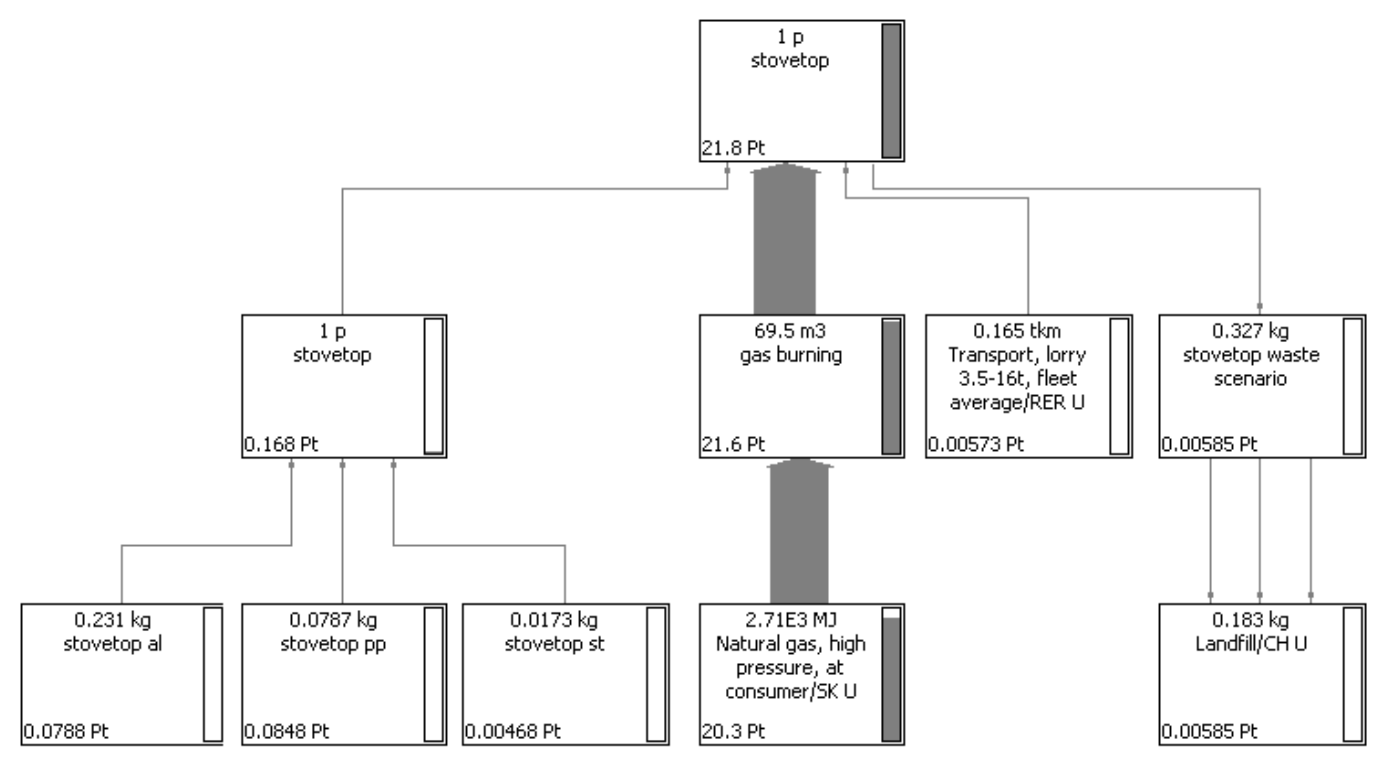

Fig. 4 Process network for life cycle of stovetop kettle

An analysis of normalization indicators shows that most environmental impact (88\%) concerns fossil fuels depletion category, that results from natural gas consumption. Indicator values for categories 'climate change' (6.5\%) and 'respiratory inorganics' (4.8\%) are results caused mainly by pollution connected with energy used for water boiling (indoor emission has been specified).

\section{Kettle comparison}

Fig. 5 presents normalization indicators for both kettles in terms of three grouped impact categories: human health, resources and ecosystem quality. The chart shows that indicators concerning the two former categories outweigh the latter one: in case of stovetop kettle ecosystem quality indicator is even negligible. However, it is still quite difficult to state unambiguously which product is better from environmental point of view.

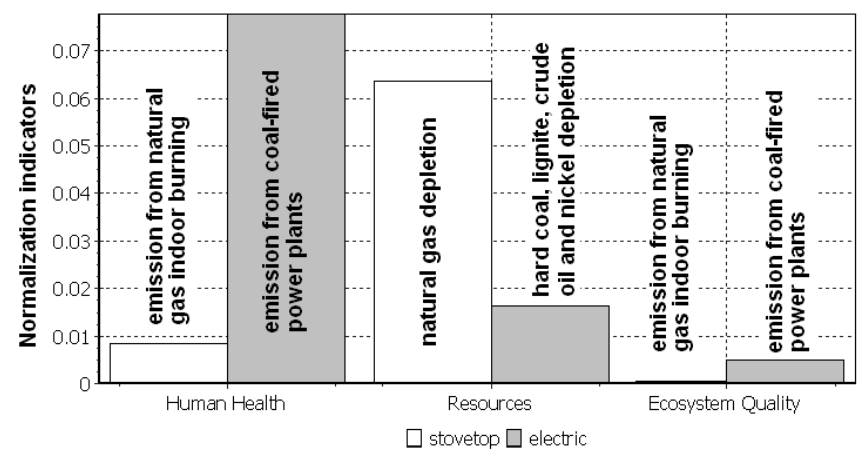

Fig. 5 Comparison of normalization indicators for stovetop and electric kettle

In case of electric kettle, majority of the life cycle impact is associated with pollution emitted from coal burning power plants that are represented by human health and ecosystem quality indicators. The product affects significantly resources: hard coal and lignite needed for electricity generation as well as raw materials necessary for manufacturing of metal and plastic components (mainly nickel and crude oil). In case of stovetop kettle, the environmental impact associated with pollution is relatively low as emission from natural gas burning is not so harmful. The life cycle impact is predominated by resources depletion that results from natural gas consumption.

Fig. 6 presents life cycle comparison of both analyzed products in terms of single score procedure according to the eco-indicator 99 method. It is clear that the stovetop kettle is more environmentally friendly than the electric one. The total environmental impact of the latter is higher by $39 \%$.

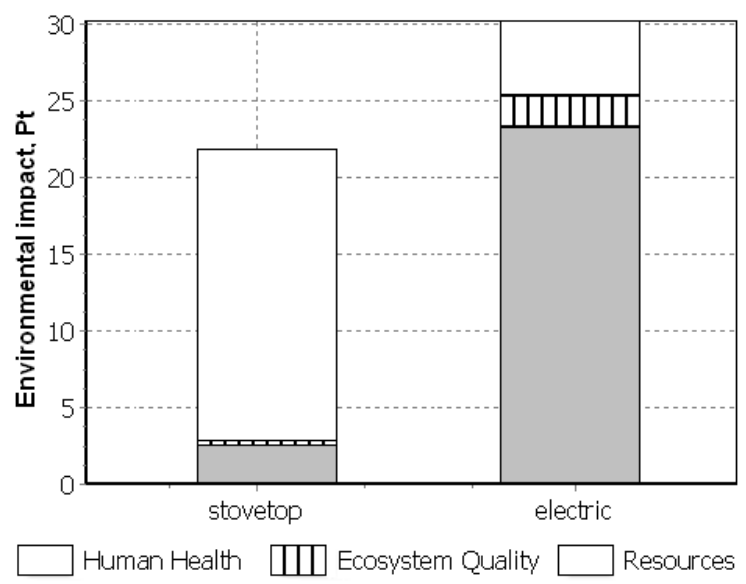

Fig. 6 Comparison of single score results for stovetop and electric kettle

The direct single score comparison is possible thanks to weighting procedure included in eco-indicator 99 method. Fig. 7 presents more general comparison of both analyzed products' life cycles. The triangle chart provides comparison of kettles avoiding arbitrary weighting procedure. As can be seen, the superiority of a given product depends on weighting coefficients. Red line represents a situation when total environmental impact of both products is equal. The yellow area of the chart represents weighting coefficient sets that result in lower total environmental impact of the electric kettle. The product is more environmentally friendly than the stovetop one only for high coefficients concerning resources and low coefficients concerning human health. 


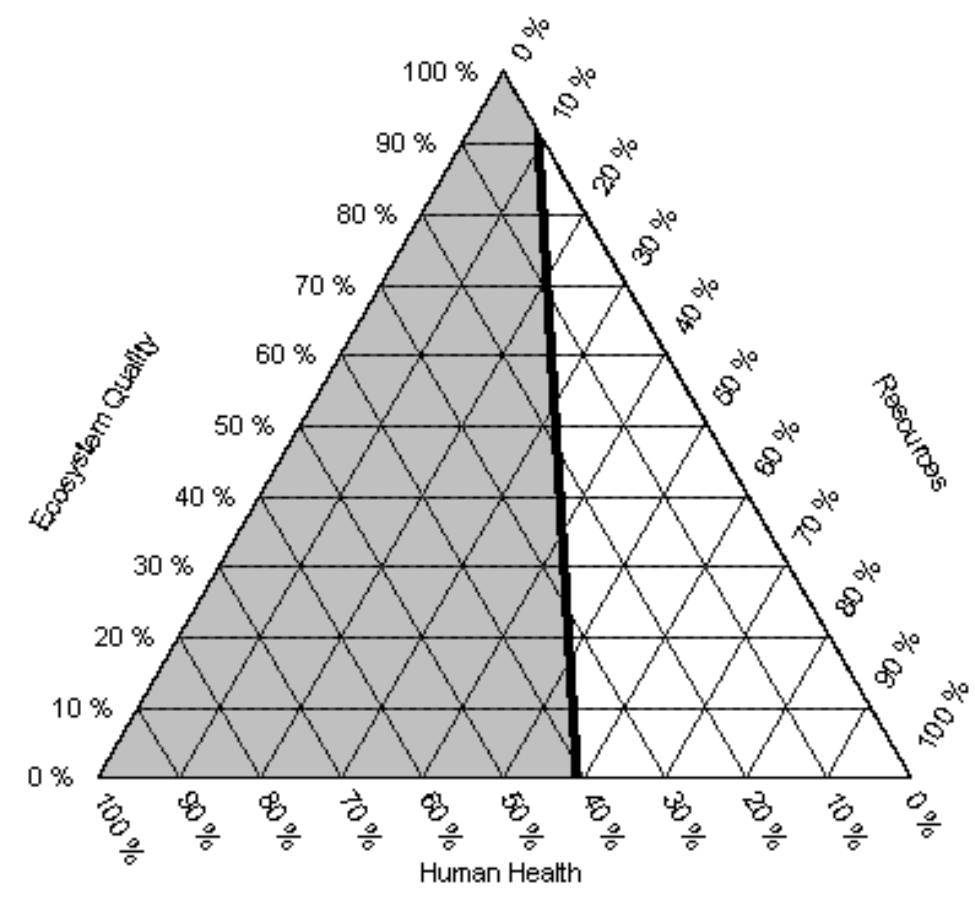

Fig. 7 The influence of weighting coefficients on results of stovetop and electric kettle comparison

However, for the rest of the chart (blue area) the stovetop kettle is better (lower environmental impact). The weighting coefficients concerning ecosystem quality are almost insignificant.

\section{Uncertainty and sensitivity analyses}

Amounts of various materials presented in Table 1 and Table 2 have been determined with very good accuracy (three decimal places). However, proposed model of products life cycle entailed some assumptions that could cause some distortion of the reality. Obtained LCA results revealed that the most significant environmental impact was associated with energy consumption for water boiling, thus assumptions connected with transport amount and waste scenario do not affect general conclusion which can be drawn from the research. Even if the amount of transport was ten times higher, the environmental impact of transport would not exceed $1 \%$ of total environmental load. Similarly, the extreme change of waste scenario assumption (recycling to landfill ratio) could change total im- pact indicator by fraction of percent only. In case of assumptions affecting energy amount needed for boiling (water volume, boiling frequency, kettle lifespan), the necessary data was assumed on basis of literature [1,9]. Fig. 5 shows that the majority of environmental impact results from electricity generation process (emission) and natural gas depletion. This result is strongly associated with local pattern of energy delivery. In this paper central European conditions were assumed (Polish electricity mix, etc.) that is why emission from coal fired power plants have dominated the impact. Fig. 8 presents comparison of the results depicted on Fig. 5 with results obtained for French conditions, where over $75 \%$ of electricity is provided by nuclear reactors, whereas hard coal fired power plants contribute less than $5 \%$ to total electricity generation [7]. Fig. 8 shows that all indicators are significantly lower for French conditions. What is interesting, in this case the electric kettle seems to be more environmentally friendly than the stovetop one (lower environmental impact). The most important effect results from natural gas resources depletion.

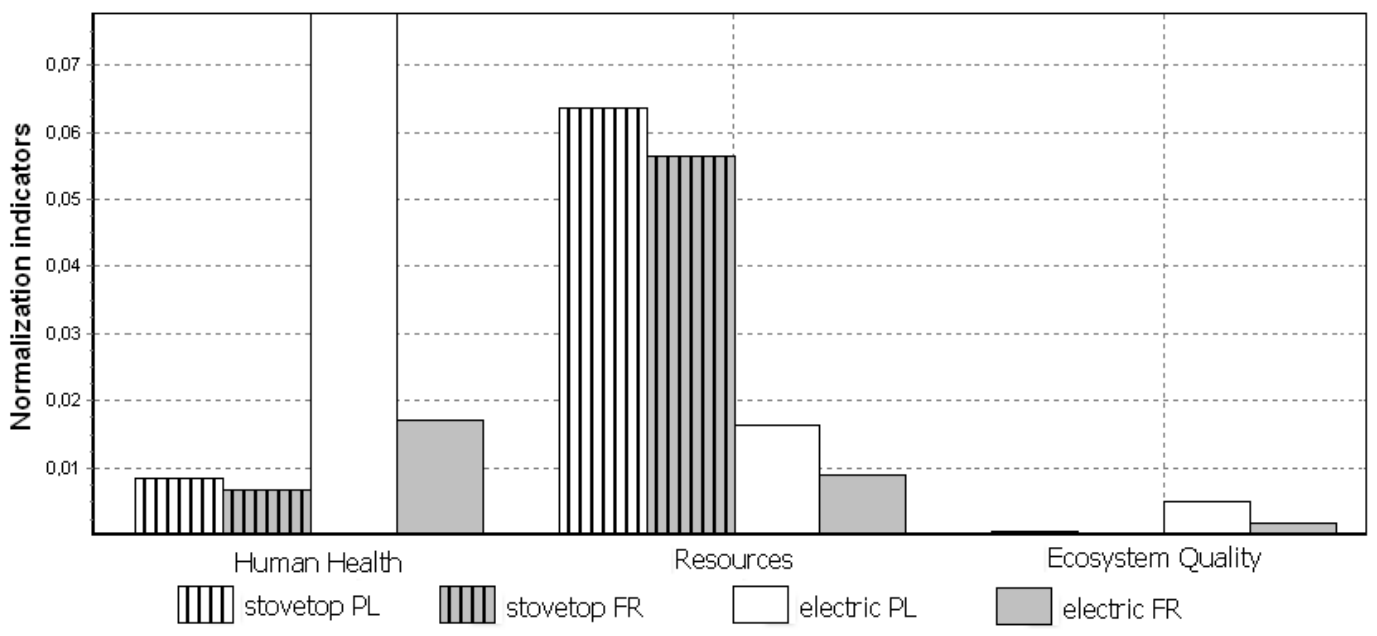

Fig. 8 Comparison of normalization indicators for Polish and French conditions 


\section{CONCLUSION}

Basing on LCA results, some improvements of products can be suggested. In case of analyzed kettles, the most significant life cycle stage concerns energy consumption needed for water boiling. Thus, the greatest opportunity to reduce environmental impact is connected with natural gas/ electricity consumption. The kettle manufacturer does not have a direct influence on this stage, but it can redesign its product to obtain higher efficiency of energy use. In case of electric kettle efficiency could be increased by boiling time optimization. The analyzed product worked by $179 \mathrm{~s}$ and turned off ca. $15 \mathrm{~s}$ after boiling had started. Thus, more precise thermostat could result in $8 \%$ reduction of total environmental impact and even more if more than $0.8 \mathrm{I}$ of water was boiled each time. In case of stovetop kettle the efficiency could be increased by application of a proper whistle, starting to indicate boiling earlier. However, it is quite difficult to estimate energy saving, as the gas stove does not turn off automatically.

Production of kettles in the form of thermos can be seen as an another way to increase energy efficiency. As the kettles are assumed to be used for three times a day, water remaining after boiling could keep temperature significantly above ambient temperature. The next boiling would start from higher initial temperature and it would use less energy. The change like this would entail higher environmental impact in assembly stage, but energy saving would outweigh this effect.

Electricity generation pattern in a given state or region has the most significant impact on comparison research results. However, also in this case, kettle manufacturers have no possibility to control this factor.

\section{REFERENCES}

[1] A. Ayoub and C. Irusta, "Comparison between Electric Kettle and Stovetop Kettle, Life Cycle Assessment Group LCA 2", Ghent University, Ghent, Belgium, 2014.

[2] V. Bhakar, A. Aashray, A.K. Digalwar and K.S. Sangwan, "Life Cycle Assessment of CRT, LCD and LED Monitors", Procedia CIRP, vol. 29, pp. 432-437, 2015.

[3] ISO 14040:2006 Environmental management - Life cycle assessment - Principles and framework, International Organization for Standardization, 2006.

[4] ISO 14044:2006 Environmental management - Life cycle assessment - Requirements and guidelines, International Organization for Standardization, 2006.

[5] ISO 14004:2016 Environmental management systems - General guidelines on principles, systems and supporting, International Organization for Standardization, 2016.
[6] ISO 14001:2015 Environmental management systems - Requirements with guidance for use, International Organization for Standardization, 2015.

[7] R. Frischknecht and M. Stucki, "Scope-dependent modelling of electricity supply in life cycle assessments", The Int. Journal of Life Cycle Assessment, vol. 15, no. 8, pp. 806-816, 2010.

[8] Gizmo Highway Website. (2016, Sept. 4). The History of the Kettle [Online]. Available: http:// www.gizmohighway.com

[9] K. Grzesik and K. Guca, "Screening Study of Life Cycle Assessment (LCA) of the Electric Kettle with SimaPro Software", Geomatics and Environmental Engineering, vol. 5, no. 3, pp. 57-68, 2011.

[10] T. Joseph, K. Baah, A. Jahanfar and B. Dubey, "A comparative life cycle assessment of conventional hand dryer and roll paper towel as hand drying methods", Science of the Total Environment, vol. 515-516, pp. 109-117, 2015.

[11] Kulinaria Website. (2017, April 23). Historia czajnika [Online]. Available: http://kulinaria.xn--wietna-dietamlc.pl

[12] D.M. Murray, J. Liao, L. Stankovic and V. Stankovic, "Understanding usage patterns of electric kettle and energy saving potential", Applied Energy, vol. 171, pp. 231-242, 2016.

[13] Regulation (EC) No 1221/2009 of the European Parliament and of the Council of 25 November 2009 on the voluntary participation by organisations in a Community eco-management and audit scheme (EMAS), repealing Regulation (EC) No 761/2001 and Commission Decisions 2001/681/EC and 2006/193/EC, EEA Joint Committee, 2009.

[14] Rozporządzenie Ministra Infrastruktury $z$ dnia 12 kwietnia 2002 r. w sprawie warunków technicznych, jakim powinny odpowiadać budynki i ich usytuowanie (Dz.U. 2002 nr 75 poz. 690), Ministerstwo Infrastruktury, 2002.

[15] Swiss Centre for Life Cycle Inventories, The ecoinvent database 2.2, data included in SimaPro 7.3 software, 2011.

[16] L. Wood. (2017, April 23). Global Household Appliances Market Worth 343.98 Billion USD by 2020 - Major Growth in China, India \& Middle East - Research and Markets [Online]. Available: http:// www.businesswire.com/news/ home/20160510006126/en/Global-HouseholdAppliances-Market-Worth-343.98-Billion

\footnotetext{
dr inż. Andrzej Marcinkowski, mgr Krzysztof Zych

Lodz University of Technology, Faculty of Organization and Management

ul. Piotrkowska 266, 90-924 Łódź, POLAND

e-mail: andrzej.marcinkowski@p.lodz.pl

krzysztofzych@zychstudio.pl
} 